Z. Klin. Chem. Klin. Biochem.

12. Jg. 1974 , S. $515-520$

\title{
Eine Zweipunkt-Methode zur Bestimmung der Harnstoffkonzentration mit einem GEMSAEC-Ana- lysengerät
}

\author{
Von R. Haeckel und D. Mathias
}

Technische Assistenz: Gudrun Runge

Institut für Klinische Chemie (Geschäftsführender Direktor: Prof. Dr. Dr. J. Büttner) Medizinische Hochschule Hannover

(Eingegangen am 24. Juni/13. August 1974)

Die Zuverlässigkeit eines Zwei-Punkt-Verfahrens zur enzymatischen Bestimmung der Harnstoffkonzentration in Serumproben wurde mit einem GEMSAEC-Analysengerät untersucht. Die Methode ist bis zu einer Konzentration von $23 \mathrm{mmol} / 1(140 \mathrm{mg} / 100 \mathrm{ml})$ linear und benötigt $5 \mu \mathrm{l}$ Serum. Proben- und Reagenzienleerwert sind nicht crforderlich. 1-13 Ergebnisse liegen in 7,3 Minuten vor. Die kritische Serienlänge des Verfahrens liegt bei etwa 180 Proben.

\section{A two point method for the determination of urea with a GEMSAEC analyzer}

The reliability of a two point method for the enzymic determination of serum urea was investigated with a GEMSAEC analyzer. The method gives a linear response up to $23 \mathrm{mmol} / \mathrm{l}(140 \mathrm{mg} / 100 \mathrm{ml})$ and it requires $5 \mu \mathrm{l}$ of serum. Sample and reagent blanks are not necessary, and 13 determinations are performed in 7.3 minutes. The critical series length for the method is about 180 samples.

Fawcett \& Scott (1) beschrieben 1960 ein Verfahren zur Bestimmung der Harnstoffkonzentration in Serum oder Plasma, bei dem nach der Urease-Reaktion die $\mathrm{NH}_{4}$-Ionen mit Natriumhypochlorit und Phenol nachgewiesen werden. Die nach Berthelot benannte Indophenol-Reaktion wird durch zahlreiche Interferenzen gestört $(2,3)$. Außerdem wurde mehrfach $(1,3)$ daraufhingewiesen, daßß dàs Mitführen eines Proben-Leerwertes für die genaue Bestimmung der Harnstoffkonzentration erforderlich ist.

Daher wurde versucht, die Indikator-Reaktion durch eine spezifischere zu ersetzen. 1965 koppelten Talke \& Schubert (4) zu diesem Zweck die Glutamatdehydrogenase- mit der Urẹase-Reaktion. Bei Serumanalysen mit mechanisierten Endpunktverfahren ist ebenfalls ein Probenleerwert oder żumindestens eine Abtrennung der Proteine erforderlich. Um diese Schritte zu umgehen, wurde die Urease-Glutamatdehydrogenase-Reaktion als Zwei-Punkt-Meßprinżip an ein Küvettenrotorverfahren adaptiert.

\section{Materialien}

\section{Kontrollseren}

Merz und Dade (D-8 München): Monitrol I und II, Labtrol und Pathotrol. Dr. Molter GmbH (D-69 Heidelberg): Seronorm. Boehringer-Mannheim GmbH (D-68 Mannheim): Precilip.

Behringwerke AG (D-355 Marburg): Kontrollserum für die Richtigkeit und Kontrollogen.

Asid Institut GmbH (D-8 München): Kontrollserum für die Richtigkeit.

\section{Standardlösung (10 mmol/l Harnstoff)}

600,6 mg Harnstoff (Merck, Katalog Nr. 8487, im Vakuum über Nacht getrocknet) wird nach Zugabe von einigen Tropfen Chloroform (Merck, Bestell-Nr: 2445) in bidest. $\mathrm{H}_{2} \mathrm{O}$ ad $1000 \mathrm{ml}$ aufgelöst. Im Kühlschrank aufbewahrt ist diese Lösung 2 Monate verwendbar.

Die Konzentration wurde gelegentlich mit NBS-Standardsubstanz (National Bureau of Standards, bezogen durch Office of Standard Reference Materials, Room B 314, Chemistry Building, National Bureau of Standards, Washington, D.C. 20234, U.S.A.) überprüft.

\section{Reaktionsgemisch}

Die Reagenzien für die Urease-Glutamatdehydrogenase-Reaktion wurden der Testpackung von Calbiochem AG (CH-600 Luzern, Kat. Nr. 869236) entnommen.

$15 \mathrm{ml}$ bidest. Wasser werden in die NADH-Flasche der Calbiochem Testcombination für den Blood Urea Nitrogen STATPACK ${ }^{\text {TM }}$ pipettiert und mit dieser Lösung der Inhalt der BUNFlasche aufgelöst.

Das fertige Reaktionsgemsich ist nach sorgfältigem Mischen bei Raumtemperatur 6 Stunden, und im Kühlschrank etwa 12 Stunden haltbar. Die Konzentrationen des Reaktionsgemisches betragen (nach Angaben des Herstellers berechnet):

Tris-Puffer (pH 7,6)

Adenosin-5-diphosphat

2-Oxoglutarat

Urease

Glutamatdehydrogenase

NADH

Alle Lösungen wcrden mit deionisiertem und quarzdestilliertem Wasser (Leitfähigkeit $<0,5 \mu \mathrm{S}$ ) angesctzt.
$62,0 \mathrm{mmol} / \mathrm{l}$

$1,34 \mathrm{mmol} / 1$

$9,0 \mathrm{mmol} / 1$

5,5 I.U. $/ \mathrm{ml}\left(30^{\circ} \mathrm{C}\right)$

$13,4 \mathrm{I} . \mathrm{U} . / \mathrm{ml}\left(30^{\circ} \mathrm{C}\right)$

$0,2 \mathrm{mmol} / \mathrm{l}$ 


\section{Geräte}

Electro Nucleonics Inc. (Fairfield 07006, U.S.A.): GEMSAEC Analyzer mit Kontrollmodul (Serien-Nummer 2113), Rotoloade (Seriennummer 3117) und Micromedic Dispenser (Sexiennummer 557 für Probe + Diluent und Seriennummer 609 für Reagenzgemisch).

Technicon GmbH (D-6368 Bad Vilbel) : SMA 12/60.

Eppendorf Gerätebau GmbH (D-2 Hamburg): Mikropipetten und Probe-Reagenzdosierer 5231.

DuPont-de Nemours (D-636 Friedberg): Automatic Clinical Analyzer (ACA).

\section{Methodik}

\section{Vorbereitung der Proben}

Die Proben wurden entweder direkt als Serum in die Probengefäße des Rotoloaders eingesetzt oder nach einer $1+10$ Verdünnung (bidest. Wasser) mit einem Probe-Reagenzdosierer.

\section{Einstellung der Geräte}

Siehe Zusammenstellung in Tabelle 1.

Je früher die erste Messung $\left(t_{1}\right)$ erfolgt, desto größer wird zwar der Meßbereich, aber auch die Streuung der Ergebnisse. Die Ursache für diesen Effekt konnte nicht geklärt werden.

Bei der hohen Ausgangsextinktion und den relativ großen Volumina (200 $\mu$ l Diluent und $500 \mu$ l Reaktionsgemisch) ist darauf zu achten, daß der Mischprozeß vor Beginn der ersten Messung weitgehend abgeschlossen ist. Dies läßt sich mit einer Bichromatlösung (5) oder NADH-Lösung prüfen: $500 \mu \mathrm{l} \mathrm{Farb-}$ lösung $=200 \mu \mathrm{l}$ dest. $\mathrm{H}_{2} \mathrm{O}$.

Die Konzentration der Farblösung sollte bei 340 nm eine Extinktion von etwa $E=1,0$ ergeben. In einem ersten Lauf läßt man die Extinktionsdifferenz zwischen 10 und 60 Sekuncien und in einem zweiten Lauf zwischen 60 und 110 Sekunden bilden (gleiches Programm wie für die Harnstoffbestimmung). Dabei muß die Präzision der Extinktionsdifferenz von Küvette zu Küvette in beiden Läufen annähernd gleich sein. Ist der Variationskoeffizient im ersten Lauf wesentlich höher, kann der Mischprozeß gestört sein.

\section{Probenfolge}

Küvette 1

2
3
$4-15$
16

Bidest. Wasser

Standardlösung (10 mmol/l)

Kontrolle, bzw. Probe

Proben

16

Probe oder Endkontrolle

Tab. 1. Einstellung des GEMSAEC-Analysensystems für die Bestimmung der Harnstoffkonzentration

a) ohne Vorverdünnung:

$\begin{array}{llrl}\text { Serum } & \mu \mathrm{l} & 5 & \text { Rotoloader } \\ \left.\text { Diluent (dest. } \mathrm{H}_{2} \mathrm{O}\right) & \mu \mathrm{l} & 200 & \text { Rotoloader } \\ \text { Reagenzgemisch } & \mu \mathrm{l} & 500 & \text { Rotoloader }\end{array}$

b) Mit Vorverdünnung:

Serum

$\mu l \quad 50 \quad$ Probe-Reagenzdosierer

Diluent (dest. $\mathrm{H}_{2} \mathrm{O}$ )

Verdünntes Serum

$\mu 1 \quad 500$ Probe-Reagenzdosierer

Diluent

$\mu \mathrm{l} \quad 50$ Rotoloader

$\mu \mathrm{l} \quad 200$ Rotoloader

1. Reading $30 \mathrm{~s}$

Reading Intervall 20s

Temperatur: $25^{\circ} \mathrm{C}$

Wellenlänge $\quad 340 \mathrm{~nm}$

Filter $\quad 335-385 \mathrm{~nm}$

Header tape: Decreasing rate reaction with ratiometric calculation

\section{Nachweisgrenze}

Bidest. Wasser wird wie eine Probe in Serie analysiert. Die Streuung der Einzelwerte ist als dreifache Standardabweichung nach Kaiser (8) ein Maß für die Nachweisgrenze.

\section{Wiederfindungsversuch}

1. 9,0 ml bidest. $\mathrm{H}_{2} \mathrm{O}+1,0 \mathrm{ml}$ Harnstofflösung (100 mmol/l), 2. $9,0 \mathrm{ml}$ Serum $+1,0 \mathrm{ml}$ Harnstofflösung $(100 \mathrm{mmol} / \mathrm{l})$,

3. $9,0 \mathrm{ml}$ Serum $+1,0 \mathrm{ml}$ bidest. $\mathrm{H}_{2} \mathrm{O}$.

Die Wiederfindung beträgt $100 \%$, wenn die Harnstoffkonzentration in Ansatz 2 gleich der Summe in Ansatz $1+3$ ist.

Interferenzen wurden nach dem gleichen Pipettierschema untersucht, indem Bilirubin- (Bilirubin Kontrollserum von Merz und Dade, D-8 München), bzw. Hämoglobin-haltige Lösungen anstelle der Harnstofflösung eingesetzt wurden. Die Hämoglobin-Lösung wurde nach Lehmann \& Hutsmann (9) hergestellt und deren Konzentration mit einer Cyan-Methämoglobin Methode (10) bestimmt.

Die Verschleppung von niedrigen zu hohen Konzentrationen $\left(Q_{1}\right)$ und von hohen $z u$ niedrigen Konzentrationen $\left(Q_{2}\right)$ wurden wie kürzlich beschrieben $(6,7)$ untersucht.

\section{Statistik}

Die Präzision-in-der-Serie wurde mit 2 identischen Kontrollproben in Küvette $4\left(x_{a}\right)$ und $5\left(x_{b}\right)$ bestimmt $(n=2 m ; m=$ Anzahl der Wertepaare):
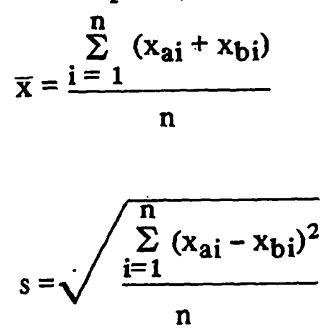

$$
\mathrm{VK}=\frac{100 s}{\overline{\mathrm{x}}}
$$

Die Präzision-von-Tag-zu-Tag wurde nach Formel (5) entweder aus den $\mathrm{x}_{\mathrm{a}}$ - oder den $\mathrm{x}_{\mathrm{b}}$-Werten berechnet $(\mathrm{n}=$ Anzahl der Werte):

$$
\overline{\mathbf{x}}_{\mathrm{a}}=\frac{\sum_{\mathrm{i}=1}^{\mathrm{n}} \mathrm{x}_{\mathrm{ai}}}{\mathrm{n}}
$$

$$
s=\sqrt{\frac{\sum_{i=1}^{n}\left(x_{a i}-\bar{x}_{a}\right)^{2}}{n-1}}
$$

\section{Ergebnisse und Diskusșion}

\section{Reaktionsbedingungen}

Es wurde davon ausgegangen, die auf dem Markt (bisher einzige) erhältliche Testkombination der Urease-Glutamatdehydrogenase Reaktion zur Bestimmung der Harnstoffkonzentration möglichst unverändert zu verwenden. Unter den gewählten Versüchsbedingungen wird der in Abbildung 1 für verschiedene Harnstoffkonzentrationen dargestellte Reaktionsverlauf beobachtet. Die vom Gerät ausgedruckte Extinktionsdifferenz ( $\Delta \mathrm{E}$ pro Minute) für die Standardkonzentration $(10 \mathrm{mmol} / \mathrm{l})$ ist chargenabhängig; sie sollte zwischen 0,12 und 0,18 (Mittelwert: 


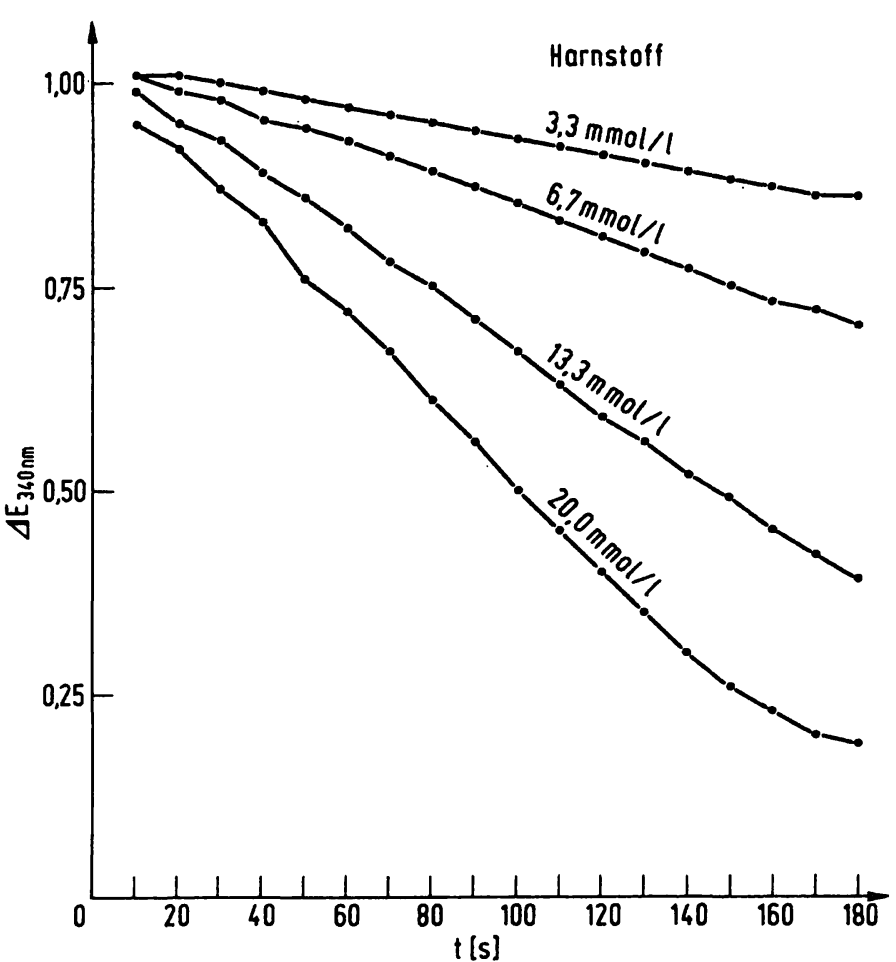

Abb. 1. Kinetik der Urease-Glutamatdehydrogenase Reaktion mit wäßrigen Harnstofflösungen verschiedener Konzentration. Die einzelnen Punkte entsprechen den ausgedruckten Meßwerten.

0,1511; Standardabweichung: $0,0 i 03 ; n=91$ ) liegen. Bei kleinerer Extinktionsdifferenz sollte das reading interval vergrößert (bis maximal 50 Sekunden), bei größerer Differenz entsprechend verringert und die
Methode mit Preciset (Boehringer Mannheim, Best.Nr. 15727) und verschiedenen Kontrollseren überprüft werden.

\section{Präzision}

Die Uberalles-Präzision des optischen und read-out Systems wurde mit Bichromatlösung untersucht und in einer vorangegangenen Mitteilung publiziert (5).

Die Präzision des Rotoloaders (Tabelle 2) ist mit unseren früheren Angaben, die mit einem anderen Modell durchgeführt wurden (5), vergleichbar. In Tabelle 3 ist die Präzision von-Tag-zu-Tag und in-der-Serie für verschiedene Kontrollseren zusammengestellt. Die Ausführungsbestimmungen und Erläuterungen zu den Richtlinien der Bundesärztekammer (Präzision von-Tag-zu-Tag: VK

Tab. 2. Präzision des Rotoloaders

\begin{tabular}{lcrlll}
\hline Station & $\begin{array}{l}\text { Volumen- } \\
\text { einstellung }\end{array}$ & $\bar{x}(\mu l)$ & $\mathrm{n}$ & $\mathrm{s}$ & $\mathrm{VK}(\%)$ \\
\hline Probe & 5 & 5,3 & 17 & 0,18 & 3,3 \\
& 50 & 49,9 & 20 & 0,29 & 0,6 \\
Diluent & $5+200$ & 203,4 & 15 & 0,42 & 0,2 \\
& $50+200$ & 248,7 & 15 & 0,16 & 0,1 \\
Reagenz & 500 & 498,8 & 20 & 0,43 & 0,1 \\
& 100 & 98,5 & 20 & 0,38 & 0,4 \\
& 200 & 198,6 & 20 & 0,38 & 0,2 \\
\hline
\end{tabular}

1) Die Volumenbestimmung erfolgte durch Auswägung von ausgestoßenem (bidest.) Wasser. Die Schlauchspitze des Pipettors wurde an den Rand des Aufnahmegefäßses gehalten.

Tab. 3. Die Präzision in-der-Serie $\left(V_{K_{s}}\right)$ und von-Tag-zu-Tag $\left(V_{K_{T}}\right)$ der Harnstoffbestimmung mit einem GEMSAEC-Analysengerät.

\begin{tabular}{|c|c|c|c|c|c|c|c|c|}
\hline Kontrollserum & $\left.\overline{\mathbf{x}}^{1}\right)$ & $\mathbf{S}_{\mathbf{s}}$ & $\mathbf{V K}_{\mathbf{s}}$ & $\left.n^{2}\right)$ & $\overline{\mathbf{x}}$ & $\mathrm{S}_{\mathrm{T}}$ & $\mathrm{VK}_{\mathrm{T}}$ & $\mathrm{n}$ \\
\hline $\begin{array}{l}\text { Monitrol I } \\
(\text { LTD-124 A) })^{3} \text { ) }\end{array}$ & 5,7 & 0,14 & 2,4 & 14 & 5,7 & 0,18 & 3,1 & 14 \\
\hline $\begin{array}{l}\text { Monitrol II }{ }^{4} \text { ) } \\
\text { PTD-32 A) }\end{array}$ & $.14,4$ & 0,16 & 1,1 & 14 & 14,4 & 0,31 & 2,15 & 14 \\
\hline $\begin{array}{l}\text { Seronorm } \\
\text { (119) }\end{array}$ & 9,2 & 0,17 & 1,9 & 14 & 9,2 & 0,19 & 2,1 & 14 \\
\hline $\begin{array}{l}\text { Labtrol } \\
\text { (LT 40 P) }\end{array}$ & 6,1 & 0,13 & 2,2 & 14 & 6,1 & 0,19 & 3,1 & 14 \\
\hline $\begin{array}{l}\text { Pathotrol } \\
\text { (PT 66 A) }\end{array}$ & 12,1 & 0,19 & 1,6 & 14 & 12,1 & 0,24 & 2,0 & 14 \\
\hline $\begin{array}{l}\text { Kontrollogen L } \\
\text { (115 C) }\end{array}$ & 3,6 & 0,13 & 3,7 & 14 & 3,6 & 0,16 & 4,4 & 14 \\
\hline $\begin{array}{l}\text { Asid Richtigkeit } \\
\text { (403 B) }\end{array}$ & 3,9 & $0,07^{\circ}$ & 1,9 & 18 & 3,9 & 0,19 & 4,9 & 18 \\
\hline $\begin{array}{l}\text { Labtrol } \\
\text { (40 P) }\end{array}$ & 6,6 & 0,07 & 1,0 & 18 & 6,6 & 0,14 & 2,1 & 18 \\
\hline $\begin{array}{l}\text { Seronorm } \\
\text { (124) }\end{array}$ & 12,6 & 0,22 & 1,8 & 18 & 12,6 & 0,22 & 1,8 & 18 \\
\hline
\end{tabular}

1) Mittelwert (mmol/l), Sțandardabweichung (s), Vạiationskoeffizient (VK) und Anzahl der Werte (n)

2) Anzahl der Wertepaare

3) Chargen-Nummer

4) Sollwert: 14,7 
$<10 \%)$ und die Forderung des College of American Pathologists (Präzision von-Tag-zu-Tag: VK $<4,2 \%$ ) werden voll erfüllt $(14,15)$. Die Dosierung von vorverdünntem Serum in einem größeren. Volumien $(50 \mu$ ) führt nicht zu einer besseren Präzision der Ergebnisse als die Pipettierung eines kleinen, unverdünnten Probenvolumens $(5 \mu \mathrm{l})$.

\section{Richtigkeit}

Das von uns gewählte Verfahren ist bis zu einer Harnstoffkonzentration von $23 \mathrm{mmol} / 1$ linear (Abb. 2). In unserem Labor werden mit diesem Bereich $94 \%$ aller anfallenden Harnstoffbestimmungen erfaßt

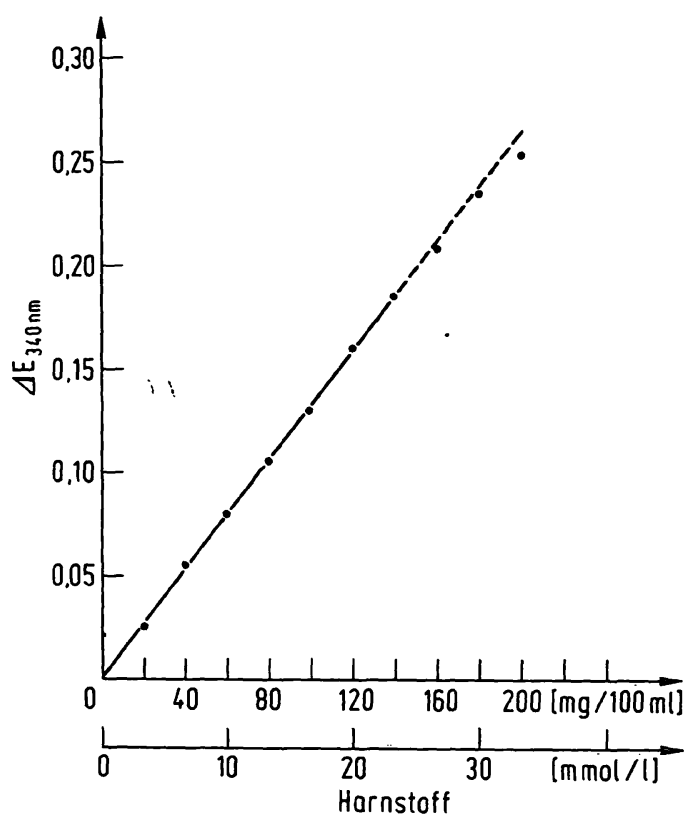

Abb. 2. Kalibriergerade der Bestimmung der Harnstoffkonzentration in wäßrigen Lösungen mit dem GEMSAEC-Analysengerät. Regressionsgerade $\mathrm{zwischen} x=0$ und $x=23 \mathrm{mmol} / \mathrm{l}: \mathrm{y}=0,007931 \mathrm{x}-0,000026, \mathrm{r}=0,9996$.
( $85 \%$ im Bereitschaftslabor, $98 \%$ in der Standardroutine, $n=3800$ ). Bei Konzentrationen über $23 \mathrm{mmol} / 1$ wird die Probe in der ersten Verdünnungsstufe 1:5 $\left(100 \mu \mathrm{l}\right.$ Serum $+400 \mu$ l bidest. $\left.\mathrm{H}_{2} \mathrm{O}\right)$ verdünnt.

Die Wiederfindungsrate betrug $96-104 \%$ in verschiedenen Humanseren (Tabelle 4). Dementsprechend fanden wir eine gute Korrelation zwischen Weŗten, die mit dem GEMSAEC- und dem ACA Gerät, sowie mit der Diacetylmonoxim Methode (SMA 12/60) bestimmt wurden (Abb. 3a, b). Ähnlich gute Úbereinstimmungen fanden wir bei Kontrollseren für die Richtigkeit (Tabelle 5 und 6). Bei einem Kontrollserum (Labtrol) trat jedoch eine deutliche Abweichung zwischen dem Sollwert und den mit den erwähnten Analysensystemen ermittelten Ergebnisseñ auf. Der Wert des GEMSAEC-Gerätes lag über dem Sollwert und dem der ACA- und SMA 12/60 Geräte.

\section{Verschleppung und Drift}

Verschleppungseffekte konnten unter den gewählten Bedingungen an verschiedenen Tagen selbst bei einer extremen Konzentrationsdifferenz von 2 und $100 \mathrm{mmol} / 1$ Harnstoff nicht festgestellt werden. Dies gilt auch bei Dosierung von 50 Mikroliter vorverdünnter Proben. Drifteffekte können ebenfalls vernachlässigt werden (5), da die zu messende Reaktion nur 50 Sekunden dauert.

\section{Interferenzen}

Lipämische Trübungen und Bilirubin stören unter den von uns untersuchten Bedingungen die Bestimmung der Harnstoffkonzentration nicht (Tabelle 4). Auch die von mehreren Autoren $(11,12)$ mit der Urease-Berthelotschen Reaktion beschriebene Hämoglobin-Interferenz wurde nicht beobachtet.

Tab. 4. Wiederfindung von Harnstoff, der verschiedenen Seren hinzugefügt wurde. Es handelt sich um mindestens 4 Bestimmungen pro Wert.

\begin{tabular}{lllll}
\hline Probe & $\begin{array}{l}\text { Harnstoff, } \\
\text { berechnet } \\
{[\mathrm{mmol} / \mathrm{l}]}\end{array}$ & $\begin{array}{l}\text { Harnstoff, } \\
\text { gefunden } 2 * \\
{[\mathrm{mmol} / \mathrm{l}]}\end{array}$ & $\begin{array}{l}\text { Wiederfindung } \\
{[\%]}\end{array}$ & $\begin{array}{l}\text { Konzentration der interferierenden } \\
\text { Substanzen }\end{array}$ \\
\hline Serum 1 & 15,3 & 15,0 & 98,0 & \\
Serum 2 & 18,0 & 17,2 & 95,6 & \\
Serum 3 & 14,4 & 14,0 & 97,2 & \\
Serum 4 & 15,4 & 15,7 & 101,9 & Triglyceride: $5,62 \mathrm{mmol} / 1$ \\
Serum 5 & 13,6 & 13,9 & 102,2 & Triglyceride: $5,20 \mathrm{mmol} / 1$ \\
Serum 6 (lipämisch) & 16,2 & 16,3 & 100,6 & Triglyceride: $5,65 \mathrm{mmol} / 1$ \\
Serum 7 (lipämisch) & 15,0 & 14,8 & 98,7 & Triglyceride: $5,03 \mathrm{mmol} / 1$ \\
Serum 8 (lipämisch) & 38,7 & 37,8 & 97,7 & Triglyceride: $4,89 \mathrm{mmol} / 1$ \\
Serum 9 (lipämisch) & 15,3 & 15,3 & 100,0 & Bilirubin: \\
Serum 10 (lipämisch) & 26,4 & 25,6 & 97,0 & $34 \mathrm{~mol} / 1$ \\
Serum 11 + Bilirubin & 9,5 & 9,1 & 95,8 & $342 \mu \mathrm{mol} / 1$ \\
Serum 12 + Bilirubin & 9,6 & 10,0 & 104,1 & Hämoglobin: $9 \mathrm{~g} / 1$ \\
Hämoglobinlösung & 10,4 & 10,4 & 100,0 & \\
\hline
\end{tabular}

* Siehe unter Methodik 

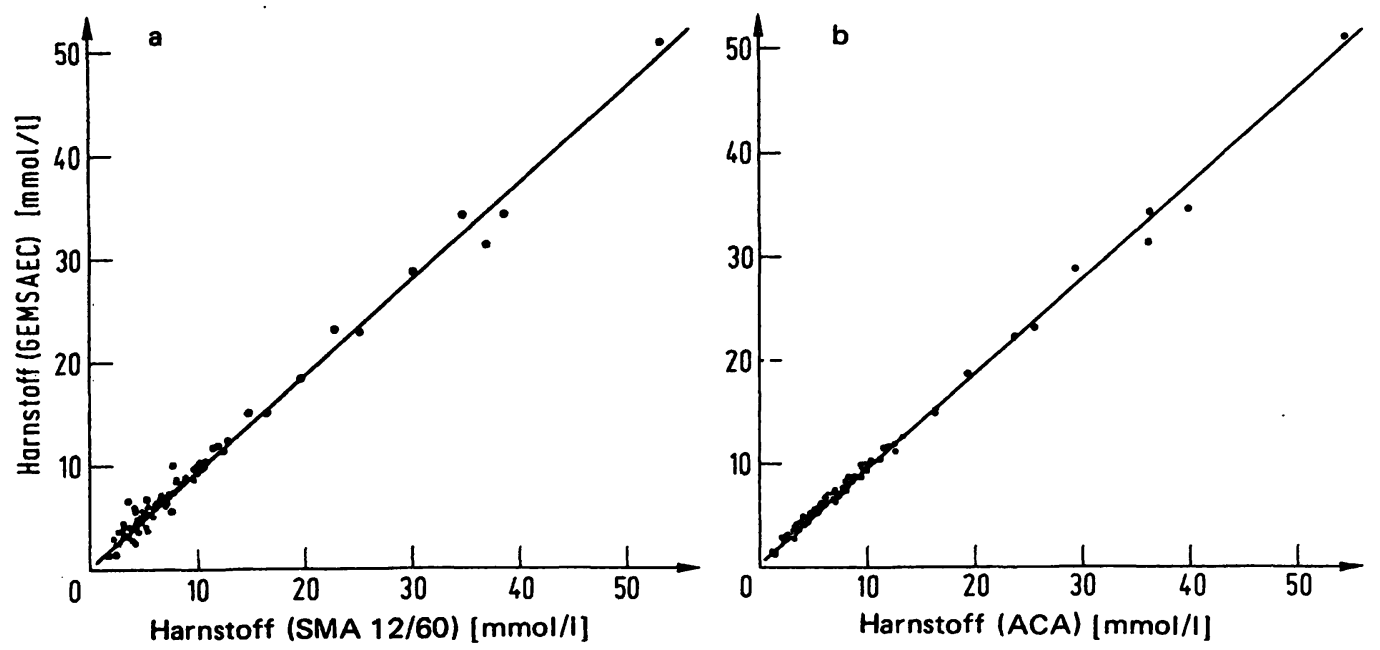

Abb. 3. Vergleichende Bestimmungen der Harnstoffkonzentration in Humanseren mit dem GEMSAEC-Analysensystem sowie dem SMA 12/60 von Technicon (a) und dem Automatic Clinical Analyzer von DuPont-de Nemours (b), die nach Vorschrift der Hersteller bedient wurden. Regressionsanalyse: a) $y=0,92 x+0,56, r=0,99(n=122$ Wertepaare); b) $y=0,91 x+0,76$, $r=0,99(n=120$ Wertepaare $)$.

Tab. 5. Richtigkeitsprüfung des Zweipunkt-Verfahrens zur Bestimmung der Harnstoffkonzentration in kommerziellen Kontrollseren.

\begin{tabular}{|c|c|c|c|c|c|c|c|c|}
\hline & $\begin{array}{l}\text { Ureas } \\
\text { (Boeh } \\
\text { Reage }\end{array}$ & $\begin{array}{l}\text { e-Berthelot } \\
\text { ringer } \\
\text { nzien) }\end{array}$ & $\begin{array}{l}\text { Urease } \\
\text { (Merck }\end{array}$ & $\begin{array}{l}\text { e-Berthelot } \\
\text { kotest) }\end{array}$ & $\begin{array}{l}\text { Diace } \\
\text { (Aut }\end{array}$ & $\begin{array}{l}\text { tylmonoxim } \\
\text { analyzer) }\end{array}$ & \multirow{2}{*}{$\begin{array}{l}\text { Gefundener } \\
\text { Wert } \\
\text { (GEMSAEC) } \\
\overline{\mathrm{x}}\end{array}$} & \multirow[t]{2}{*}{ Chargen-Nummer } \\
\hline & $\left.\overline{\mathbf{x}}^{1}\right)$ & $\bar{x} \pm 2 s$ & $\overline{\mathbf{x}}$ & $\bar{x} \pm 2 s$ & $\bar{x}$ & $\bar{x} \pm 2 s$ & & \\
\hline $\begin{array}{l}\text { Monitrol I } \\
\text { Monitrol II } \\
\text { Labtrol } \\
\text { Pathotrol } \\
\text { Seronorm } \\
\text { Seronorm } \\
\text { Precilip } \\
\text { Kontrollogen } \\
\text { Asid Richtigkeit } \\
\text { Behring Richtigkeit }\end{array}$ & $\begin{array}{r}5,9 \\
18,0 \\
6,6 \\
11,2\end{array}$ & $\begin{array}{r}5,2-6,6 \\
16,3-19,7 \\
6,1-7,1 \\
9,9-12,5 \\
12,5 \\
9,4 \\
4,3-5,2 \\
3,7 \\
4,7 \\
6,0\end{array}$ & $\begin{array}{r}5,6 \\
17,0 \\
7,0 \\
12,5 \\
11,7-13,3 \\
8,7-10,1 \\
\\
3,3-4,0 \\
4,0-5,3 \\
5,4-6,6\end{array}$ & $\begin{array}{r}4,9-6,3 \\
15,3-18,7 \\
6,5-7,5 \\
11,2-13,8 \\
3 \\
1 \\
0 \\
3 \\
6\end{array}$ & $\begin{array}{r}5,7 \\
17,5 \\
6,5 \\
11,4 \\
13,0 \\
9,4\end{array}$ & $\begin{array}{r}5,0-6,4 \\
15,8-19,2 \\
6,0-7,0 \\
10,1-12,7 \\
12,7-13,3 \\
8,9-9,9\end{array}$ & $\begin{array}{r}\left.5,7^{2}\right) \\
\left.16,8^{3}\right) \\
\left.7,9^{2}\right) \\
\left(2,5^{3}\right) \\
\left(2,6^{2}\right) \\
\left.9,2^{2}\right) \\
\left.4,2^{3}\right) \\
\left.3,6^{2}\right) \\
\left.3,9^{2}\right) \\
\left.6,2^{3}\right)\end{array}$ & $\begin{array}{l}\text { LTD-124 A } \\
\text { PTD-29 A, B } \\
\text { LT-38 A } \\
\text { PT-65 A } \\
124 \\
119 \\
312 \\
115 \mathrm{C} \\
403 \mathrm{~B} \\
117 \mathrm{P}\end{array}$ \\
\hline
\end{tabular}

1) auf dem Beipackzettel angegebener Sollwert und Vertrauensbereich

2) Standardabweichung: Siehe Tabelle 3 bzw. Tabelle 6

3) Mittelwert aus mindestens 2 Bestimmungen.

Tab. 6. Vergleichende Bèstimmung der Harnstoffkonzentration in 3 Kontrollseren (Chargennummer und Sollwerte: Siehe Tabelle 5) mit verschiedenen Analysensystemen. Der Automatic Clinical Analyzer von DuPont-de Nemours und der SMA 12/60 von Technicon wurden nach Vorschrift der Hersteller bedient. Manuelles Verfahren: Merckotest Nr. 3334. Die Zahlen bedeuten Mittelwerte $(\mathrm{mmol} / \mathrm{l})$ und Standardabweichung (in Klammer), Anzahl der Werte: $\mathbf{n}=18$.

\begin{tabular}{lclll}
\hline $\begin{array}{l}\text { Analysen- } \\
\text { system }\end{array}$ & GEMSAEC ACA & \multicolumn{2}{c}{ SMA $12 / 60$} & Manuell \\
\hline Labtrol & 7,9 & 6,2 & 6,6 & 7,3 \\
& $(0,43)$ & $(0,08)$ & $(0,20)$ & $(0,5)$ \\
Pathotrol & 12,5 & 11,4 & 11,3 & 12,5 \\
& $(0,43)$ & $(0,21)$ & $(0,22)$ & $(0,63)$ \\
Asid - & 3,9 & - & 4,6 & 4,6 \\
Richtig- & $(0,09)$ & & $(0,16)$ & $(0,29)$ \\
keit & & & & \\
Seronorm & 12,6 & - & 12,6 & 12,0 \\
& $(0,37)$ & - & $(0,15)$ & $(0,74)$ \\
Labtrol & 6,6 & - & 5,4 & 5,5 \\
& $(0,26)$ & & $(0,13)$ & $(0,48)$ \\
\hline
\end{tabular}

\section{Nachweisgrenze}

Die nach Kaiser berechnete Nachweisgrenze betrug $0,14 \mathrm{mmol} / 1$ (Mittelwert aus 3 Serien à 14 Werten). Richterich \& Küffer (11) haben vor kurzem ein alternatives Verfahren zur Bestimmung der Nachweisgrenze vorgeschlagen. Danach wird die Standardabweichung gegen den jeweiligen Mittelwert in ein Koordinatensystem eingezeichnet. Bei linearer Auftragung schneidet die Regressionsgerade die Ordinate in einem bestimmten Punkt, der als Schätzgröße für die Standardabweichung bei der theoretischen Konzentration „Null“ bezeichnet werden kann (Abb. 4). Multipliziert man den Ordinatenschnittpunkt mit 3, so stimmt der erhaltene Wert $(0,14 \mathrm{mmol} / \mathrm{l})$ bei der beschriebenen Bestimmung der Harnstoffkonzentration gut mit der nach Kaiser ermittelten Nachweisgrenze überein.

\section{Wirtschaftlichkeit}

Die kritische Serienlänge gibt an, wieviel Proben pro Tag in einer Serie mindestens anfallen müssen, damit 


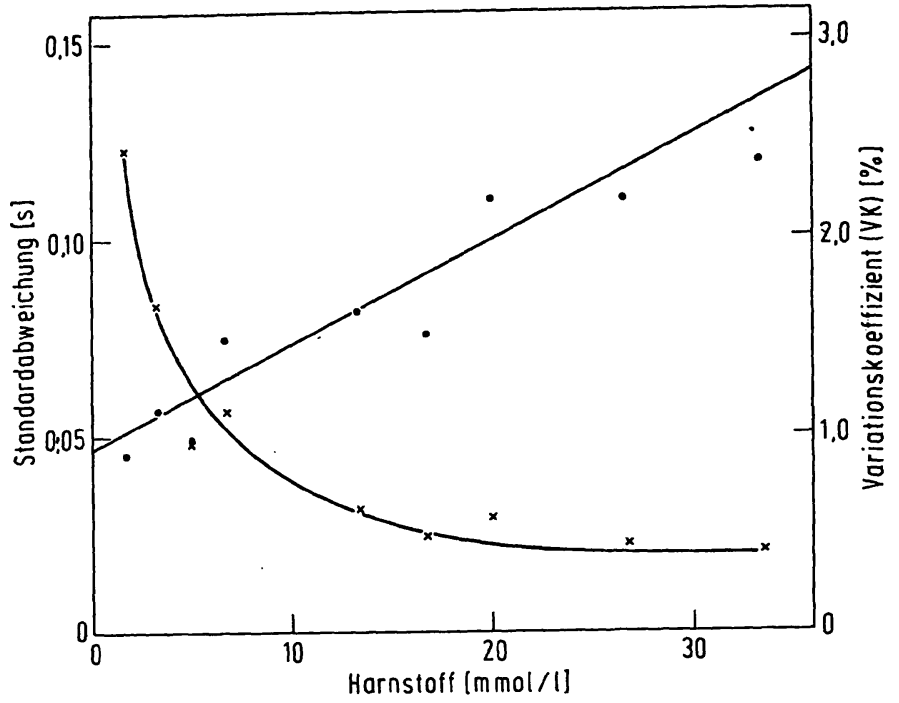

Abb. 4. Standardabweichung $(\bullet-\bullet)$ und Variationskoeffizient $(x-x)$ in Abhängigkeit von der Harnstoffkonzentration bei der enzymatischen Zweipunkt-Bestimmung mit einem GEMSAEC-Analy sengerät. Regressionsgerade der Standardabweichung: $y=0,0023 x+0,0469$, $\mathrm{r}=0,9379$.

der Einsatz eines mechanisierten Analysensystems wirtschaftlich wird. Die Schätzung dieser Größe kann mit Formeln durchgeführt werden, die kürzlich mitgeteilt wurden (13). Bei der kritischen Serienlänge sind die Gesamtkosten, die sich aus fixen und variablen Kosten zusammensetzen, für das mechanisierte und eine manuelle Vergleichsmethode gleich groß. Die verwendeten Analysenzeiten für das manuelle Verfahren entsprechen früheren Angaben (13) und für das GEMSAECSystem den Ausführungen in Tabelle 7. Unter diesen Bedingungen beträgt die kritische Serienlänge für die Harnstoffbestimmung etwa 186 Proben (Tabelle 8). Dieser Wert liegt wegen der im Vergleich zur manuellen Methode teuereren Reagenzien relativ hoch. Er zeigt aber in Übereinstimmung mit früheren Schätzungen (13) daß die Anschaffung eines solchen Systems erst wirtschaftlich wird, wenn etwa 200 Analysen pro Tag durch- geführt werden können. Die Umrüstzeit fällt dabei mit dem GEMSAEC-System kaum ins Gewicht.

Tab. 7. Analysenzeit (Minuten) pro Rotor (13 Proben, 1 Leerwert, 1 Standard, 1 Präzisionskontrolle) für die enzymatische Harnstoffbestimmung mit einem GEMSAEC Gerät.

Füllen des Rotors mit Rotorloader

Umsetzen des Rotors

Analysenzeit einschließlich des Ergebnis-Ausdruckes $\quad 2,8$

Gesamtzeit des 1 . Laufes

Gesamtzeit der folgenden Läufe $\quad 4,5$

Tab. 8. Die kritische Serienlänge für die enzymatische Harnstoffbestimmung mit dem GEMSAEC Analysengerät im Vergleich zu einer manuellen Methode mit der Boehringer Testcombination Nr. 15930. Die Preise sind den Listen der Hersteller vom letzten Quartal 1973 entnommen. Personalkosten: $0,22 \mathrm{DM} / \min (13)$.

Methode Manuell (A) GEMSAEC (B)

a) Fixe Kosten ( $\left.K_{f}\right)$

I. Gerätekosten

II. $3 \%$ von I

III. Glaswaren

IV. Einmalmaterial pro Serie

V. Reagenzienkosten für Leerwert, Standard und Präzision

$\mathrm{K}_{\mathrm{f}}=(\mathrm{I}+\mathrm{II} \times 5) / 1800+\mathrm{III} /$

$100+I V+V$

\begin{tabular}{lrr} 
(DM) & $\left.8.627,20^{1}\right)$ & $163.609,00$ \\
(DM) & 258,82 & $4.908,00$ \\
(DM) & 223,20 & - \\
(DM) & 0,30 & \multicolumn{2}{c}{0,13} \\
(DM) & 0,51 & -
\end{tabular}

(DM) $\quad 8,5 \dot{5}$

104,66

b) Variable Kosten

I. Einmalmaterial pro Probe

II. Reagenzienkosten pro Probe

III. Analysenzeit $t_{1}$

$t_{2}$

(DM) $\quad 0,17$

(min) 50

(min) 320 (100 Proben) (104 Proben)

roben)

40,8

Kritische Serienlänge ${ }^{3}$ ) 178

1) Eppendorf Photometer, 1 Wasserbad, 3 Eppendorf-Pipetten $(20,100,200 \mu \mathrm{l}), 2$ Absaugvorrịchtungen, 1 Küvettenhalter, 1 Filter $546 \mathrm{~nm}$.

2) einschließlich Reagenzienkosten für Standard- und Kontrollprobenwert pro Lauf.

3) Berechnet nach Gleichung 4 aus l.c. (13).

\section{Literatur}

1. Fawcett, J. K. \& Scott, J. E. (1960) J. Clin. Pathol. 13, 156-159.

2. Lorentz, K. (1967), diese Z. 5, 291-298.

3. Richterich, R. (1973), diese Z. 11, 553-564.

4. Talke, H. \& Schubert, G. E. (1965), Klin. Wochenschr. 43, 174-175.

5. Haeckel, R. (1973), diese Z. 11, 234-248.

6. Haeckel, R. \& Porth., A. J. (1972), diese Z. 10, 91-94.

7. Haeckel, R. (1972), diese Z., 10, 235-242.

8. Kaiser, H. (1965), Z. Analyt. Chem. 209, 1-18.

9. Lehmann, H. \& Huntsman, R. G. (1966), Man's haemoglobins. North-Holland Publishing Co., Amsterdam. 10. Drabkin, D. L. \& Austin, J. H. (1935), J. Biol. Chem. 112,
51-88.

11. Richterich, R. \& Küffer, H. (1973), diese Z. 11, 553-564.

12. Shull, B., Cheng, Ch. \& Rahill, W. J. (1973), Clin. Chem. 19,1226 .

13. Haeckel, R., Höpfel, P. \& Höner, G. (1974), diese Z. 12, 1422.

14. Ausführungsbestimmungen und Erläuterungen zu den Richtlinien der Bundesärztekammer zur Durchfưhrung der statistischen Qualitätskontrolle und von Ringveruschen im Bereich der Heilkunde (1974). Deut. Ärzteblatt 71, 961964.

15. Büttner, J., Hansert, E. \& Stamm, D. (1970), in (U. Bergmeyer, Hrsg.): Methoden der Enzymatischen Analyse, Verlag Chemie Weinheim, 282-364.

Prof. Dr. R. Haeckel

3 Hannover

Karl-Wiechert-Allee 9 